\title{
Argumentos para uma abordagem discursiva das práticas de linguagem no trabalho
}

\author{
Arguments for a discursive approach of language practices in work \\ Décio Rocha \\ Universidade do Estado do Rio de Janeiro/CNPq - Rio de Janeiro - Rio de Janeiro - Brasil
}

Bruno Deusdará

Universidade do Estado do Rio de Janeiro - Rio de Janeiro - Rio de Janeiro - Brasil

$\diamond$

\begin{abstract}
Resumo: A motivação para a escritura do presente artigo é oriunda de demanda a nós encaminhada por pesquisadores da área da saúde visando a interlocuções teóricas referentes às possibilidades e limites de uma abordagem conteudista das práticas de linguagem. Nosso interesse no referido debate reside em avaliar tais possibilidades e limites, à luz de alguns dos pressupostos que sustentam uma abordagem discursiva (MAINGUENEAU, 1989). A título de ilustração, recorremos a textos midiáticos que tematizam situações bastante recorrentes em trabalhos que adotam metodologicamente alguma técnica preconizada pela análise de conteúdo, a exemplo das condições em que se dão os procedimentos de entrevista. Observamos que o recurso a dispositivos metodológicos de tal ordem é coetâneo de uma determinada imagem de mundo que se pretende legitimar: um mundo que privilegia as formas constituídas, não abrindo espaço para outros embates de forças e para a produção de novos modos de vida.
\end{abstract}

Palavras-chave: Práticas discursivas; Trabalho; Análise de conteúdo; Análise do discurso

\begin{abstract}
The motivation for writing this paper comes from the demand put forward by researchers dealing with the field of health who wished to question the theoretical possibilities and limitations of the practical content-language approach. Our interest in the debate lies in evaluating such possibilities and limits in the light of some assumptions underpinning a discursive approach (MAINGUENEAU, 1989). As an illustration, we turn to media texts that analyze recurring situations in studies which adopt methodologically a technique advocated by content analysis, such as the conditions in which they conceive interview procedures. We observed that the use of such methodological devices goes in pair with a certain image of the world that we intend to legitimize: a world that privileges established forms, avoiding other clashes of forces and the production of new ways of life.
\end{abstract}

Keywords: Discursive practices; Work; Content analysis; Discourse analysis

Vários são os caminhos que levam à formalização e consolidação de grupos de pesquisa no país, iniciativa sempre incentivada pela impossibilidade de se conceber na atualidade uma atividade de pesquisa que não esteja assentada em uma perspectiva plural. Dentre esses caminhos, identificamos desde aqueles que encontram sua razão de ser no cumprimento de exigências dos órgãos de fomento, na necessidade de dar visibilidade ao conjunto de trabalhos que se desenvolvem em uma determinada linha de pesquisa integrante de um Programa de pósgraduação, nas afinidades em torno de uma dada temática ou área de atuação, dentre outras motivações possíveis.
Situado na interface linguagem e trabalho, o artigo que ora desenvolvemos é fruto de uma interlocução que vem se produzindo junto a um coletivo de pesquisadores que, em meio a experimentações diversas na área, souberam encontrar pontos de afecção que sempre intensificaram sua potência de agir e de pensar ${ }^{1}$, instituindo laços de trabalhos que conciliam a produtividade das pesquisas realizadas e o prazer do encontro.

$\mathrm{Na}$ verdade, o interesse do grupo pela área remonta a meados dos anos 1990, por ocasião da constituição do

\footnotetext{
1 Acolhemos aqui o sentido espinoziano do termo afecção.
} 
GR-Pesq Atelier ${ }^{2}$, quando tiveram início as primeiras experiências na área (SOUZA-E-SILVA; MACHADO, 1998) e também quando se oficializou um Acordo Capes-Cofecub (SOUZA-E-SILVA e FAÏTA, 2002; RICHARD-ZAPPELLA,1999), iniciativa que trouxe uma importante contribuição por oportunizar o diálogo entre pesquisadores brasileiros e franceses. Mais recentemente, o grupo avançou nesse movimento de consolidação ao se configurar em 2006 como um grupo de trabalho da Anpoll, o qual se intitulou Linguagem, Enunciação e Trabalho. Hoje, o referido GT reúne pesquisadores de vários pontos do país e vem oportunizando variadas experiências de trabalho que ganham corpo em publicações conjuntas e individuais.

Temos conseguido resultados interessantes trabalhando na interface de diferentes práticas de trabalho e dos estudos da linguagem, e também em pesquisas voltadas para o que denominamos "discursos sobre o trabalho", campo de atuação que vem constituindo uma especificidade das investigações em curso no Brasil (ROCHA, DAHER e SANT'ANNA, 2002). Nossa abordagem das práticas de linguagem se define como uma abordagem discursiva cujo perfil procuraremos delimitar ao longo deste artigo. Na verdade, interrogar nosso quadro teórico à luz das práticas linguageiras que se atualizam no trabalho tem representado um caminho bastante importante no sentido de pôr à prova esse mesmo quadro, experimentando sua produtividade e avaliando a pertinência dos resultados que vem propiciando. Assim, aproveitaremos a oportunidade oferecida por este artigo para falar ainda uma vez sobre as vantagens de uma abordagem discursiva frente a outras abordagens de cunho conteudístico que, por diferentes razões, parecem ainda se manter em posição hegemônica, se considerarmos as experiências que vêm se realizando em diferentes pontos das áreas de saúde e das ciências sociais no país.

Nesse contexto, a ideia de redação do presente artigo origina-se de demanda a nós encaminhada em agosto de 2013 por profissionais do Instituto Nacional do Câncer (Inca) no Rio de Janeiro, que, envolvidos em atividades de pesquisa que compreendiam entrevistas e outros procedimentos de coleta / produção de informação, desejavam uma interlocução com outras áreas que também se interessassem pelo debate teórico-metodológico em que estavam seriamente engajados.

Como profissionais da área de saúde, interessavalhes o debate sobre metodologias de pesquisa e, em particular, sobre os caminhos apontados pela Análise de Conteúdo. Conheciam a proposta de L. Bardin (2009) e já haviam realizado experiências com ela quando

\footnotetext{
2 O grupo Atelier é sediado na PUC-São Paulo, no Programa LAEL, por iniciativa de Cecília de Souza-e-Silva.
}

tiveram a oportunidade de conhecer artigo por nós publicado anteriormente (ROCHA; DEUSDARÁ, 2006) que justamente colocava em questão a distância entre a Análise de Conteúdo e a Análise do Discurso.

Consideramos extremamente oportuna a demanda de um encontro para tratarmos do tema. Acreditamos que, dentre as formações profissionais voltadas para questões de linguagem, o linguista tem uma contribuição importante a oferecer, em especial se, complementarmente, ainda detém uma formação de base discursiva. Com isso, não pretendemos fortalecer especialismos, pois acreditamos que várias são as formações que lidam necessariamente com práticas linguageiras, e cada uma delas terá certamente uma importante parcela de conhecimentos a disponibilizar. O que queremos, sim, reafirmar é que, nesse contexto, a parcela oferecida pelo linguista-analista do discurso não é de menor interesse que as demais, o que reforça a necessidade de um diálogo mais intenso e mais regular com esse profissional.

Este texto estará, desse modo, organizado segundo um percurso bastante direto e que, por isso mesmo, nos pareceu adequado aos propósitos de abertura de uma interlocução com outras áreas: primeiramente, uma breve retrospectiva da Análise de conteúdo, explicitandose seus princípios de base; a seguir, breve diálogo em torno de textos midiáticos que tematizam a situação de entrevista, dispositivo metodológico largamente utilizado pelos profissionais de saúde com os quais estabelecemos contato, a fim de explicitar algumas das limitações de uma perspectiva conteudista; seguem-se reflexões sobre algumas das implicações da adoção de uma abordagem conteudista no que diz respeito ao perfil de mundo que então será possível apreender; finalmente, caracterização, em linhas gerais, de caminhos que consideramos produtivos para a apreensão das práticas de linguagem, tomando-se por base princípios que acolhemos de uma perspectiva discursiva.

\section{O que foi, o que vem sendo a Análise de conteúdo?}

Das primeiras décadas do século XX, nos Estados Unidos, a este início de um novo século que ora vivemos, a Análise de conteúdo vem fazendo prova de uma resistência e de um poder de penetração surpreendentes, não, talvez, na área dos estudos da linguagem propriamente dita, mas em um vasto leque de áreas afins das ciências humanas e sociais, a exemplo da psicologia, do serviço social, da educação, além de ainda encontrar uma larga acolhida em pesquisas na área da saúde, como foi relatado acerca da situação que deu origem a este artigo. Com efeito, é muito recorrente a menção a uma metodologia (quando não a uma "técnica") de análise das interações verbais com 
base nas orientações de uma abordagem conteudística, em especial, no Brasil, nas preconizações de Bardin (2009).

Os objetivos dessa Análise de conteúdo parecem ainda hoje permanecer fiéis àqueles que caracterizaram seus primórdios, que podemos localizar na obra de autores como Lasswell, Berelson, Lazarsfeld, dentre outros $^{3}$. No Brasil, como dissemos, é bastante forte a presença de Bardin, para quem, por detrás do discurso aparente, geralmente simbólico e polissêmico, escondese um sentido que convém desvendar mediante o recurso a um conjunto de técnicas. Eis como a autora define literalmente o projeto de uma análise de conteúdo:

Um conjunto de técnicas de análise das comunicações visando obter, por procedimentos, sistemáticos e objetivos de descrição do conteúdo das mensagens, indicadores (quantitativos ou não) que permitam a inferência de conhecimentos relativos às condições de produção/recepção (variáveis inferidas) destas mensagens. (BARDIN, 2009, p. 11)

As diferentes técnicas de AC costumam organizar-se, segundo Bardin (2009), em 3 etapas: a préanálise, a exploração do material e o tratamento dos resultados.

A pré-análise é a etapa em que tem lugar o primeiro contato com os documentos: momento de uma "leitura flutuante" visando à formulação dos objetivos do trabalho e das questões norteadoras, assim como, se for o caso, das primeiras hipóteses. Nessa etapa, define-se o córpus ${ }^{4}$ de pesquisa, escolhem-se os índices sobre os quais incidirá a ação do pesquisador para a organização de indicadores escolhas que estarão embasadas nas questões norteadoras ou nas hipóteses.

A seguir, passa-se à exploração do material - é o momento da codificação, em que os dados brutos são transformados de forma organizada e agregados em unidades que deverão permitir descrever as características pertinentes do conteúdo.

A codificação se dá em 3 etapas: (i) escolha de unidades de registro (recorte), isto é, escolha das unidades de significação a codificar (um tema, uma palavra ou uma frase); (ii) seleção de regras de contagem (enumeração), em que a presença ou a ausência de elementos podem ser significativas, assim como a frequência de uma unidade de registro, sua intensidade, direção, ordem da aparição e situações de coocorrência; (iii) escolha de categorias e eventuais subcategorias (por classificação e agregação), entendendo-se por categoria uma forma geral de conceito, reflexo da realidade, síntese do saber que apresenta minimamente as seguintes propriedades: são exclusivas, homogêneas e pertinentes. Acrescente-se que essa etapa de categorização representa o momento de passagem dos dados brutos aos dados organizados: faz-se o inventário de elementos e, a seguir, classificam-se estes elementos, impondo organização à mensagem.

Finalmente, o tratamento dos resultados representa o momento das inferências (orientadas pelos diversos polos de atração da comunicação - emissor, receptor, mensagem) e interpretação dos dados, com o objetivo de buscar o que se esconde sob a aparente realidade, o que significa verdadeiramente o discurso enunciado.

Como em todo e qualquer investimento que se faça em um determinado caminho de pesquisa, algo se ganha e algo se perde quando se opta pela análise de conteúdo: por um lado, a análise de conteúdo possibilita o acesso a uma macroestrutura textual de conteúdos, logrando ainda lidar com um córpus bastante extenso; por outro lado, tendo em vista a ênfase no dito, a análise de conteúdo perde algo da singularidade das enunciações e, embasada em uma concepção de linguagem transparente, privilegia generalizações e representações de uma realidade objetivada.

\section{O que entendemos como insuficiências da Análise de conteúdo?}

Em primeiro lugar, queremos desde já prevenir o leitor de que, ao tematizarmos as insuficiências de uma abordagem conteudista, não cobraremos da Análise de conteúdo nada que ela não se proponha a fazer ${ }^{5}$. Por essa razão, não polemizaremos, por exemplo, acerca das insuficiências teóricas que encontramos nas pesquisas na área, quando se parte de uma concepção homogênea de sujeito. Se a Análise de conteúdo se define, segundo o constatam aqueles que a praticam, como uma metodologia, é para aspectos metodológicos que convergirá o nosso olhar.

Apesar de muitas pesquisas pretenderem se caracterizar como qualitativas, muitos investimentos em Análise de conteúdo encontram-se centrados no levantamento de percentuais de ocorrência de determinadas categorias e sua consequente produção de gráficos, contentando-se então com algumas poucas observações de leitura desses mesmos gráficos como garantia do selo "pesquisa qualitativa".

Há, com certeza, a esse respeito, temas que se prestam mais do que outros a tais estatísticas. Um exemplo de tal

\footnotetext{
Ver, a respeito do histórico da Análise de conteúdo (ROCHA \& DEUSDARÁ, 2006).

4 Dada a frequência de uso do termo na área dos estudos da linguagem, pensamos ser adequado contribuir para que córpus (forma única no singular e no plural, a exemplo de "lápis") alcance a condição de palavra da língua portuguesa a ser dicionarizada. Aliás, uma rápida busca da grafia "córpus" no Google acadêmico já nos indica ser essa uma iniciativa apoiada por muitos

5 Para uma reflexão sobre os efeitos dessas insufiências metodológicas e possíveis alternativas em perspectiva discursiva na coleta de dados, em especial na pesquisa de campo, remetemos o leitor a Deusdará (2013).
} 
procedimento de geração de gráficos é apresentado na figura a seguir:

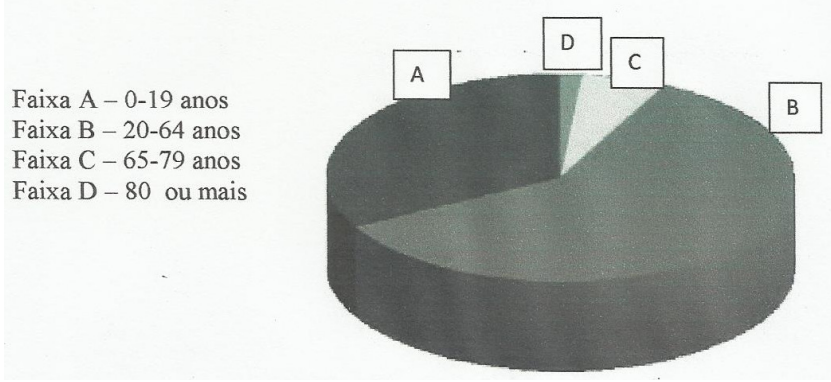

Figura 1. Distribuição da população brasileira por faixa etária - censo IBGE $2010^{6}$

Há, no entanto, temas que oferecem alguma resistência a tal modo de representação, como seria o caso de um gráfico que representasse os resultados de uma olimpíada de matemática entre os alunos do Ensino Médio de uma escola, os quais foram assim distribuídos: $20 \%$ dos alunos - ótimo; $60 \%$ dos alunos - bom; $15 \%$ dos alunos - regular; $5 \%$ dos alunos - ruim.

$\mathrm{O}$ que se entende por essas categorias - ótimo, bom, regular, ruim - não pode ser definido senão por intermédio de uma nova codificação arbitrária, como seria o caso ao se estabelecerem patamares definidores de cada categoria em função do número de pontos alcançados pelos participantes da olimpíada. Por exemplo: ruim - de zero a 499 pontos; regular - de 500 a 749 pontos; bom - de 750 a 899 pontos; ótimo - de 900 a 1000 pontos.

Podemos ainda lembrar o exemplo de situações em que não se apresenta qualquer possibilidade de delimitação precisa de sentido entre as categorias utilizadas. Este parece ser o caso de um levantamento de dados acerca de questões como "O que você acha do cinema brasileiro?", quando os resultados se expressam em categorias previamente apresentadas aos entrevistados como as elencadas a seguir: adoro, aprecio bastante, gosto razoavelmente, não me agrada muito, detesto. Não é preciso uma longa reflexão para nos darmos conta de que é bastante impreciso o uso dessas categorias. Afinal, como medir a distância entre "aprecio bastante" e "gosto razoavelmente"?

Situações como essas que exemplificamos de modo simplificado, apresentando apenas os gráficos que costumam ser usados em levantamentos de opinião, ocorrem efetivamente em muitas pesquisas que recorrem

\footnotetext{
6 Gráfico adaptado de alfanumericus.blogspot.com.br/2012/01/pensandoum-pouco-no-futuro-nao-somos.html
}

a uma metodologia da análise de conteúdo. Este parece ser o caso da pesquisa de Sá et al. (2008), cujo objetivo é assim apresentado pelos autores:

descrever os conteúdos das memórias históricas sobre o regime militar no Brasil (1964-1985) construídas em três grupos etários, analisá-los comparativamente e identificar as diferenças existentes no âmbito de cada grupo em função do nível de escolaridade e da orientação política dos seus membros. (SÁ et al., 2008, p. 38)

Com efeito, no sentido de conhecer os conteúdos da memória da população que habita o município do Rio de Janeiro a respeito do regime militar no Brasil, foi aplicado um questionário de 31 perguntas. Para tal fim, três grupos etários são construídos: jovens (de 15 a 21 anos em 2003), adultos (de 34 a 60 anos em 2004) e idosos (65 anos ou mais em 2005), num total de 842 sujeitos. Três categorias de orientação política também são propostas: esquerda (incluindo centro-esquerda), direita (incluindo centro-direita) e sem orientação política definida. Uma das tabelas constantes do artigo - a saber, a tabela 2 - reúne dados relativos a cada um dos grupos etários em função da orientação política. A título de exemplo, uma leitura da tabela nos informa que, dentre os jovens, foram entrevistados 77 de orientação política de esquerda, 83 de direita e 274 sem orientação definida (SÁ et al., 2008, p.41). Mais adiante, na tabela 4, tomase conhecimento de que a opinião dos jovens se divide quando são questionados sobre a natureza das ações empreendidas pelo governo militar: 23,04\% acreditam que fizeram "mais coisas boas", 73,27\% pensam que fizeram predominantemente "coisas ruins", 3,69\% "não sabem ou não lembram".

O que nos preocupa em procedimentos metodológicos como o exposto pode ser resumidamente apresentado como se segue:

(i) não se define o que se entende por essas categorias de orientação política, como "ser de esquerda" ou "ser de direita";

(ii) não se define o que se entende por "coisas boas" ou "coisas ruins" feitas durante o governo militar; trata-se de categorias que podem ser tão enganosas quanto as que mostraremos a seguir, em levantamento de opinião acerca do que pensam as pessoas sobre as manifestações ocorridas recentemente no país;

(iii) não se tem acesso às 31 perguntas do questionário aplicado, tampouco a qualquer resposta analítica fornecida pelos entrevistados, quando este é o caso.

Trataremos a seguir com algum detalhamento esses casos. 
Em (i) e (ii), questiona-se a legitimidade das categorias com as quais se lida na pesquisa. Com efeito, ser de direita ou de esquerda são posicionamentos bastante pouco precisos, principalmente se considerarmos a diversidade de critérios que pode ter desempenhado um papel importante nessa opção. Em (ii), a criação de categorias como "coisas boas" e "coisas ruins" é igualmente vaga. Expomo-nos aqui ao mesmo tipo de risco que rege a formulação de um conceito, segundo a perspectiva de Nietzsche:

Acreditamos saber algo das coisas mesmas, se falamos de árvores, cores, neve e flores, que de nenhum modo correspondem às entidades de origem. [...]

Toda palavra torna-se logo conceito justamente quando não deve servir, como recordação, para a vivência primitiva, completamente individualizada e única, à qual deve seu surgimento ... Todo conceito nasce por igualação do não igual. (NIETZSCHE, 1978, p. 47-48)

Assim, percebe-se o risco que se corre quando se procede à "igualação do não igual": incluímos numa mesma categoria coisas diversas, negligenciando a singularidade de cada termo. É precisamente disso que se trata quando a Análise de conteúdo recorre, como procedimento metodológico, à anulação das diferenças entre diferentes termos para criar, na interseção daquilo que possuem em comum, uma única categoria.

Para ilustrar algumas das consequências de tal procedimento metodológico, lançamos mão de uma situação em que algo de semelhante acontece, por ocasião de uma enquete feita pela rádio Mais FM106.1, junto a 228 pessoas, em julho de 2013 (RÁDIO MAIS FM106.1, 2013). A enquete versava sobre as manifestações populares ocorridas no Brasil em 2013, quando a população saiu às ruas para reivindicar serviços públicos de qualidade (saúde, educação, transporte) e protestar contra a corrupção. A pergunta dirigida aos ouvintes da rádio era "O que você pensa sobre as manifestações no Brasil? Comente!". Como resultado da enquete, 165 pessoas (72,4\% do total) escolheram a opção "Muito bom, porque o povo acordou". Além de marcarem a referida opção, ainda acrescentaram comentários, atendendo ao solicitado, e é precisamente sobre esses comentários que incide nossa atenção ${ }^{7}$. A razão de nosso interesse por tais comentários é bastante simples: a grande categoria criada pela enquete promovida pela rádio dos que marcaram "muito bom, porque o povo acordou" reúne,

\footnotetext{
Lembremos aqui que, se recorremos, como exemplificação, a uma enquete realizada por uma rádio, é porque, em geral, as pesquisas na área de Análise de conteúdo não nos oferecem acesso aos questionários ou entrevistas que formulam, nem à materialidade dos textos produzidos pelos sujeitos.
}

na realidade, posicionamentos bastante distintos, se for dada atenção ao modo como enunciam suas justificativas. A diversidade de justificativas que reside sob uma mesma categoria demonstra o silenciamento que se encontra na base de qualquer pretensão de categorização de aspectos tão pouco dados a segmentações. Senão, passemos à transcrição de alguns dos comentários desses ouvintes:

o brasileiro está acordando e vendo a situação que
nosso pais enfrenta
o povo acordou!
$\underline{\text { O brasil ficou calado por muito tempo }}$
$\underline{\text { o povo brasileiro só acorda quando apanha }}$
$\underline{\text { a população está acordando }}$
$\underline{\text { As pessoas acordaram sobre o que está acontecendo }}$
$\underline{\text { a sociedade esta abrindo os olhos }}$
$\underline{\text { nós iremos atrás do nossos direitos }}$
é direito do cidadão expressar seu modo de pensar
a classe trabalhadora é cada vez mais explorada
a nova geração não está dormindo
(RÁDIO MAIS FM106.1, 2013)

Como se percebe com alguma facilidade, há uma grande distância, do ponto de vista enunciativo, entre os diferentes agentes aos quais se atribui a responsabilidade das manifestações. Afinal, atribuir tal responsabilidade ao brasileiro, ao Brasil, à população ou à socidade é coisa bem diferente de atribuí-la a nós, à classe trabalhadora ou à nova geração. Por essa razão, estamos convencidos de que dizer apenas que todos os comentários se igualam por apoiarem as manifestações não significa muita coisa. O que se perde é exatamente o potencial da diferença em favor da vontade de apreender as repetições.

Passemos a um último comentário, também extraído do referido site, de um ouvinte que também apoiou as manifestações no país.

Eu não digo que não se deve hever mudanças, e as manifestações são uma cobranças pra essas. Mais acho errado usarem partido no meio. (RÁDIO MAIS FM106.1, 2013)

O que nos chama a atenção neste último comentário é precisamente, após a identificação de 11 reformulantes, o reiterado apagamento do agente dessas manifestações. No sentido de perceber que o enunciador insiste em tal apagamento, explicitemos as escolhas linguísticas feitas: uso do verbo haver, impessoal ("não digo que não se deve hever mudanças"; nominalizações ("manifestações", "cobranças"); sujeito indeterminado, com verbo na 3 " pessoa do plural ("acho errado usarem partido no meio").

Assim, à guisa de conclusão, se podemos falar de uma única categoria de ouvintes que assumem um mesmo posicionamento de aprovação dessas manifestações, é 
igualmente certo que há diferenças importantes entre eles: mais uma vez, retomando Nietzsche, diremos que se igualou o não igual - procedimento que gera alguns frutos, mas não sem cobrar o seu preço.

Ainda sob a ótica enunciativa, queremos registrar um outro aspecto que a simples inclusão de sujeitos na categoria "favoráveis às manifestações" não permitiu ser apreciado. Referimo-nos aqui à diversidade de escolhas enunciativas feitas pelos ouvintes para expressar seu apoio às manifestações nos comentários feitos:

- expressão de uma opinião: "Acho muito bom"

- expressão de um sentimento: "tô muito confiante que depois de tantas manifestações o Brasil vai ser o melhor lugar do mundo pra se viver."

- uma narração: "Aqui em Curitiba estou vendo movimentos estranhos do exército pela cidade se continuar esses quebra quebra será que vamos entrar num regime militar, devido as normas de segurança."

- palavras de ordem - "MANIFESTAÇ̃̃O POPULAR" NÃO PODE PARAR! EI VOCÊ AI, ME DÁ UM DINHEIRO AI, PARA A EDUCAÇÃO E SAÚDE"

- discurso relatado: "Já dizia Ulisses Guimarães (a única coisa que político tem medo é do povo na rua)"

Para finalizar este item que diz respeito às insuficiências da Análise de conteúdo tal como ela vem sendo praticada, passemos aos problemas levantados pela não visibilidade do questionário enquanto dispositivo responsável pela emissão de opiniões sobre os eventos em questão. Com efeito, as pesquisas que se servem de uma técnica de análise de conteúdo costumam omitir não apenas os dispositivos construídos pelo pesquisador (questionários, entrevistas), mas também as respostas que são oferecidas. Parece haver um certo descaso em relação à materialidade linguística, como se, no fundo, a linguagem fosse transparente e não carecesse de problematização. É o que sucintamente procuraremos sustentar com base em uma entrevista realizada no âmbito da disciplina Metodologia de Investigação em Contexto online, do Mestrado de Pedagogia do Elearning, 5a edição, da Universidade Aberta, Lisboa, a qual serviu de córpus para uma análise de conteúdo. Vejamos o fragmento da entrevista escolhido para ilustrar de que modo a confecção de perguntas pode conter pressupostos que, de algum modo, orientam a resposta do entrevistado:

(1) Entrevistadora: queria começar por perguntar o que significa pa ti o termo ensino a distancia?

Entrevistado: Significa poder aprender à distancia e ter acesso a recursos que dificilmente conseguirias obter fisicamente
(2) Entrevistadora: e quanto a ensino/formação online? e elearning? são para ti a mesma coisa que ensino a distãncia? o que entendes por cada um deles?

Entrevistado: Penso que ensino a' distancia compreende uma maior interactividade professor aluno, e o ensino/formacao e elearning a utilizacao de um "software" educativo sem a possibilidade de partilha de ideias com outros interveniente. [...]

(3) Entrevistadora: eheh consideras que essas são vantagens do ensino a distancia? relativamente ao tipo de ensino em que temos que nos descolar para uma escola?

Entrevistado: sim, considero. que sao vantagens do ensino a distancia. A distancia geografica entre os internientes nesta aprendizagem deixa de ser um obstaculo na aprendizagem.

(4) Entrevistadora: que outras designaçoes conheces para ensino a distanci?

Entrevistado: ensino online elearning [...]

(5) Entrevistadora: O Ensino a Distância é vantajoso em relação ao Ensino Presencial?

Entrevistado: Penso que e' uma alternativa, mas $n$ o considero melhor. Para mim o modelo classico de aprendizagem presencial para mim continua a fazer o mais eficaz. (ANÁLISE DE CONTEÚDO DE ENTREVISTA, 2012).

Observa-se que, em (2), ao se perguntar o que o entrevistado entende por cada uma das expressões solicitadas (ensino online, formação on line, e-learning, ensino a distância), já lhe é antecipada a possibilidade de serem "a mesma coisa". Curiosamente, em (4), indaga-se o entrevistado exatamente sobre o que já lhe foi antecipado em (2). Algo da mesma ordem parece ocorrer em (3), quando, ao se perguntar ao entrevistado como ele avalia uma dada situação, formula-se o enunciado já indagando se se trata de vantagens do ensino a distância. Ainda uma vez o mesmo tipo de procedimento se repete em (5): para indagar sobre a posição do entrevistado acerca da diferença entre ensino a distância e ensino presencial, o locutor lhe pergunta se aquele é vantajoso em relação a este. Como se percebe, o acesso às questões formuladas pelo entrevistador pode ser um dispositivo fundamental na avaliação das respostas fornecidas.

\section{Que qualidade de mundo se produz ao se propor apreender esse mundo com ênfase nos conteúdos?}

Ao final do primeiro item deste artigo, já havíamos destacado que um aspecto a ser ressaltado em uma perspectiva conteudista residiria em permitir o acesso 
a uma macroestrutura textual dos conteúdos, o que se explica pela possibilidade de se lidar com um conjunto considerável de textos. Neste item, privilegiaremos um breve debate acerca do modo como essa opção contribui para configurar uma certa qualidade de mundo que se pretende investigar.

Um primeiro aspecto a ser observado aponta para a ênfase em uma concepção informacional. Tal ênfase se afirma no modo como se preconiza o tratamento dos textos submetidos ao exame do pesquisador, o que garante sua passagem ao estatuto de dados a serem analisados. Já nos referimos às etapas que se iniciam com a pré-análise, passando pela exploração do material e, ao final, o mundo em que se explicitam as inferências do pesquisador. Assim configuradas, essas etapas fazem supor que somente ao final de um tratamento objetivo é que seriam permitidas tais inferências. Até lá, a pretensão é de que tudo se caracterize pelo maior grau de objetividade possível.

Procede-se, dessa maneira, a um percurso, na verdade, objetivante dos textos, que se propõe a dessingularizá-los, a deles extrair o que há de comum e, principalmente, a fazer ver a atuação do pesquisador a partir de uma postura supostamente distanciada em relação aos dados. Observa-se assim o modo como se apagam as implicações do pesquisador com seu objeto de pesquisa, relação travada desde a elaboração do projeto, passando por toda a trajetória de definição de objeto e procedimentos. Assim, desejamos ressaltar que, diferentemente do que se sugere com essas etapas, a leitura que o pesquisador faz de seus córpus se inicia antes mesmo de qualquer "coleta objetiva de dados".

Ressalte-se ainda que essas etapas metodológicas parecem afirmar uma compreensão de leitura como atividade de mera decodificação, o que é demonstrado pela aposta em um privilégio do dito como possibilidade única de acesso aos sentidos. Ler um texto é, segundo tal perspectiva, tão somente decifrar as palavras desse texto.

Como contraponto desse tipo de concepção de leitura, recuperamos um trecho da reflexão de M. Bakhtin a respeito do estatuto de locutor sob uma perspectiva dialógica da linguagem:

O desejo de tornar seu discurso inteligível é apenas um elemento abstrato da intenção discursiva em seu todo. O próprio locutor como tal é, em certo grau, um respondente [...], pois não é o primeiro locutor, que rompe pela primeira vez o eterno silêncio de um mundo mudo, e pressupõe não só a existência do sistema da língua que utiliza, mas também a existência dos enunciados anteriores - emanantes dele mesmo ou do outro - aos quais seu próprio enunciado está vinculado por algum tipo de relação (fundamenta-se neles, polemiza com eles), pura e simplesmente ele já os supõe conhecidos do ouvinte. Cada enunciado é um elo da cadeia muito complexa de outros enunciados. (BAKHTIN, 2000, p. 291)
Ao assumir que os enunciados não contêm um sentido a ser desvendado, o autor privilegia a existência de uma cadeia de enunciados em relação aos quais qualquer texto emerge como um posicionamento. Seu ponto de vista destaca que a condição para a produção e circulação de textos é a existência de uma cadeia prévia muito complexa do qual um novo texto se torna mais um elo. Tal propriedade dos textos se perde, quando a ênfase se dá sobre as palavras isoladas como unidade de signficação: a leitura deixa de ser um diálogo único, um ato de enunciação para ser compreendida como mero instante de decodificação.

Outro aspecto igualmente importante se afirma no necessário debate conceitual que deve envolver também os dispositivos metodológicos. Tendo sido originalmente destacado por M. Pêcheux (In: GADET; HAK,1997) como algo cuja relevância havia sido ignorada pelos interessados em Análise de conteúdo, os questionários e os demais instrumentos utilizados no acesso a certos dados não só estão implicados com uma determinada concepção teórica, como também contribuem para produzir uma dada qualidade de mundo à qual só é possível ter acesso por meio dessas formas.

Antes de retomar nos exemplos anteriormente citados aspectos que reafirmem o que dizemos acima, gostaríamos de destacar aqui que o que nos é apresentado como argumento para a opção por esse tipo de perspectiva é fundamentalmente a adequação a um imperativo característico da ciência moderna: a ideia de que o acesso a uma grande quantidade de dados conduziria a saberes com maior potencial universalizante.

A garantia oferecida se sustenta em crer que um grande número de textos submetido a exame de técnicas de contagem de frequências e ocorrências de itens permitiria neutralizar o caráter enganoso da supercíficie textual singular. Dessa forma, o ímpeto universalizante, ao propor assegurar a inclusão do pesquisador nos ideais da ciência moderna, não deixa de fazer ver o funcionamento de uma maquinaria que compreende o significado como realidade pré-existente e escondida sob a superfície textual. A única forma de acessá-la estaria no investimento em uma ordem transcendental, na qual o pesquisador estaria protegido dos investimentos de sentido produzidos pelos textos apreendidos singularmente. A condição do olhar residiria em abandonar os textos singularmente configurados para tomá-los por percentuais de frequência e ocorrência de itens.

Para constituir um lugar seguro, reconhecido pela Modernidade como posição legítima para a produção de saberes científicos, o que se assume como real a que se teria acesso com tal perspectiva é um mundo de formas estabelecidas e visíveis, tais como os percentuais de alunos ruins, regulares, bons e ótimos, da olimpíada de 
matemática referida anteriormente. Merece destaque que o que se evidencia no exemplo mencionado é mais do que a atribuição de rótulos explicitamente avaliativos a um dado grupo de candidatos, mas a própria criação das faixas para as quais eles são atribuídos. Ainda poderíamos ler uma vez mais os objetivos de uma pesquisa citada anteriormente (SÁ et al., 2008), observando o que pressupõem: (i) as memórias históricas se repartem em três grupos etários; (ii) há diferenças nos conteúdos dessas memórias em relação a níveis de escolaridade. Não precisaríamos dizer muito acerca do que se privilegia como segmentos tomados como existentes previamente à pesquisa.

Um mundo que privilegia formas dadas e visíveis é o que se prevê em uma concepção contratualista de Estado Moderno. Trata-se de um cenário em que se neutraliza o potencial de ação justamente por não se pretender lidar com o campo social como espaço/tempo de embate de forças para a progressiva criação de novas formas visíveis. Neutraliza-se a ação do pesquisador no próprio engendramento dos "dados" em favor de uma postura universalizante.

A apropriação e criação de regras e códigos que comandam a interpretação dos acontecimentos pelos intérpretes do poder, seja do ponto de vista político, econômico ou midiático, impõem o que se deve pensar, como se deve agir e em que ou quem acreditar, sob a guilhotina dos prêmios ou dos castigos por Bem ou por Mal, pelo útil ou nocivo, pelo legal ou ilegal, sempre conforme ao sentido dominante dado pelo poder em questão. (FUGANTHI, s/d, 5)

\section{Considerações finais: impossibilidade de restringir o sentido ao dito}

Cabe-nos, ao final das reflexões aqui desenvolvidas, fazer minimamente algumas considerações que nos parecem relevantes para caracterizar um contorno teórico da perspectiva discursiva que acolhemos, em contraponto às limitações das abordagens conteudistas discutidas anteriormente.

Por todo o exposto, parece ter destaque o modo como, do ponto de vista do conteudismo, é possível dar resposta ao ímpeto de universalidade que sustenta o pensamento moderno. Ao privilegiar o dito como principal componente a ser inspecionado para apreensão do significado, a Análise de Conteúdo conduziu a uma redução extrema do que caracteriza uma interação verbal, que acabou ficando limitada a seu resultado material isto é, limitada ao plano do dito.

Propondo uma trajetória de reflexões que procura restituir a complexidade da dinâmica das trocas verbais, a Análise do Discurso parte da evidência de que não é possível dizer qualquer coisa, a qualquer um e em qualquer lugar ou de qualquer modo, para mencionar apenas algumas das coerções a que se submete a produção de enunciados. Trata-se aqui de uma observação muito simples e, ao mesmo tempo, de uma complexidade que exige a reconfiguração do próprio projeto de construção de verdade(s). Vemo-nos, desse modo, diante de uma nova perspectiva sobre as práticas de linguagem que nos lança inevitavelmente em uma teorização a respeito da situação mais imediata em que um determinado dito é proferido, bem como do contexto sócio-histórico mais amplo que interdita, seleciona, estimula certos dizeres em detrimento de outros. A necessária teorização a que somos convocados por tal evidência nos leva a reflexões como a que transcrevemos a seguir, da autoria de Foucault (2004), em A ordem do discurso:

[...] em toda sociedade a produção do discurso é ao mesmo tempo controlada, selecionada, organizada e redistribuída por certo número de procedimentos que têm por função conjurar seus poderes e perigos, dominar seu acontecimento aleatório, esquivar sua pesada e temível materialidade. (FOUCAULT, 2004, p. 8-9)

De acordo com tal perspectiva, perdem força perguntas como "quem fala?" e "com que intenção?", passando-se a iluminar as tensões que fundamentam toda tomada da palavra. Com efeito, para o analista do discurso, a situação de troca verbal passa a ser compreendida a partir de uma outra ordem de questões: quem pode enunciar uma ordem? como se autoriza a fazê-lo? quem pode "recebê-la"? em que circunstâncias? a respeito de quais temas? Questões que, como podemos perceber, implicam um aprofundamento das condições de produção, circulação e consumo dos discursos, colocando em cena um quadro teórico no qual minimamente deveriam figurar os seguintes elementos:

- a noção de prática discursiva (MAINGUENEAU, 1989), entendida como a produção simultânea de textos e de uma comunidade que produz esses textos e que, por intermédio desses mesmos textos, acaba ganhando visibilidade;

- a noção de enlaçamentos, entendida como "processos pelos quais o texto de uma formação discursiva reflete sua própria enunciação" (MAINGUENEAU, 1989, p.69), implicando necessariamente o investimento em uma dada modalidade de inter-relação entre locutores, em um etos, em um código linguageiro, enfim, em diferentes dispositivos enunciativos por meio dos quais um texto instaura aquela legitimidade que ele paradoxalmente pressupõe de início. 
De fato, as incompatibilidades evidenciadas em relação a aspectos conceituais que envolvem desde uma concepção de linguagem a definições como a de texto, bem como a compreensão acerca da prática de leitura, apenas dão acesso a um debate que merece atenção por parte daqueles que optam por uma perspectiva discursiva: um movimento de busca por verdades sempre perspectivas, orientado não por um entendimento apaziguador das formas constituídas, mas pelo potencial de intervenção das práticas de linguagem, procurando restituir a possibilidade de deriva das interações verbais em ato.

\section{Referências}

ANÁLISE DE CONTEÚDO DE ENTREVISTA, 2012. Disponível em docs.google.com/Doc?docid=0AVkxsrzQHIMh ZGNwcTdyeGhfMThnczlzdm5jdw\&hl=en. Acesso em: 3 set. 2013.

BAKHTIN, Mikhail. Estética da Criação Verbal. Trad. de Maria Ermantina Galvão. São Paulo: Martins Fontes, 2000, p. 291.

BARDIN, Laurence. Análise de Conteúdo. Trad. de Luís Antero Reto e Augusto Pinheiro. Edição Revista e Atualizada. Lisboa: Edições 70, 2009.

DEUSDARÁ, Bruno. Pesquisa de campo em análise do discurso: construindo um dispositivo de aproximação aos sentidos do trabalho no cotidiano escolar. Signum. Estudos de Linguagem, v. 16, p. 35-57, 2013.

FUGANTI, Luiz. Ética como potência e Moral como servidão. Disponível em: <http://www.luizfuganti.com.br/ escritos/textos/68-etica-como-potencia-e-moral-comoservidao? format $=$ pdf $>$. Acesso em: 28/11/2013.

MAINGUENEAU, Dominique. Novas Tendências em Análise do Discurso. Trad. de Freda Indursky. Campinas, SP: Pontes, 1989.

NIETZSCHE, Friedrich. Sobre verdade e mentira no sentido extramoral. Trad.de Rubens Rodrigues Torres Filho. Os Pensadores. São Paulo: Abril Cultural, 1978.
PÊCHEUX, Michel. Análise Automática do Discurso (AAD69). In: GADET, F.; HAK, T. (Org.). Por uma análise automática do discurso: uma introdução à obra de Michel Pêcheux. Trad. de Bethania S. Mariani et al. 3. ed. Camínas: Ed. da Unicamp, 1997. p. 61-162.

RÁDIO MAIS FM106.1. Enquete sobre manifestações populares no Brasil. Disponível em: maisfm.org.br/enquetes/10-oque-voce-pensa-sobre-as-manifestacoes-no-brasil-comente. Acesso em: 1 set. 2013.

RICHARD-ZAPPELLA, Jeannine. Présentation. In: RichardZappella, J. (Org.). Espaces de travail, espaces de parole. Rouen: PUR, 1999.

ROCHA, Décio. Le questonnaire et les discours de l'entreprise: dialogue ou monoloque? In: Richard-Zappella, J. (Org.). Espaces de travail, espaces de parole. Rouen: PUR, 1999.

ROCHA, Décio; DAHER, Del Carmen; SANT'ANNA, Vera Lucia de A. Produtividade das investigações dos discursos sobre o trabalho. In: SOUZA-E-SILVA, M.C.P.; FAÏTA, D. (Org.). Linguagem e Trabalho: construção de objetos de análise no Brasil e na França. São Paulo: Cortez, 2002.

ROCHA, Décio; DEUSDARÁ, Bruno. Análise de conteúdo e Análise do discurso: o linguístico e seu entorno. DELTA. Documentação de Estudos em Lingüística Teórica e Aplicada, São Paulo, v. 22, n. 1, p. 29-52, 2006.

SÁ, Celso P. et al. A memória histórica do Regime Militar em três gerações: conteúdos factuais e juízos críticos. Psicologia: Teoria e Prática, v. 10, n. 1, p. 36-51, 2008.

SOUZA-E-SILVA, Maria Cecília P. Maintenant... on va faire une parenthèse... pour laver notre linge sale: écarts entre travail prescrit et travail réel. In: RICHARD-ZAPPELLA, J. (Org.). Espaces de travail, espaces de parole. Rouen, PUR. p. 139-150, 1999.

SOUZA-E-SILVA, Maria Cecília P.; MACHADO, Anna Rachel (Org.). The Especialist, São Paulo: Educ, v. 19, n. esp., 1998.

SOUZA-E-SILVA, Maria Cecília P.; FAÏTA, Daniel (Org.). Linguagem e trabalho: construção de objetos de análise no Brasil e na França. São Paulo: Cortez, 2002.

Recebido: 12 de março de 2014

Aprovado: 25 de abril de 2014

Contato: rochadm@uol.com.br; brunodeusdara@gmail.com 